\title{
THE MOVEMENT OF FLUID THROUGH THE HUMAN CAPILLARY WALL IN RELATION TO VENOUS PRESSURE AND TO THE COLLOID OSMOTIC PRESSURE OF THE BLOOD
}

\author{
By A. KROGH, E. M. LANDIS ${ }^{1}$ AND A. H. TURNER 2 \\ (From the Laboratory of Zoophysiology, Unizersity of Copenhagen, Copenhagen, Denmark)
}

(Received for publication June 27, 1931)

It is well established by experiments on normal human subjects that when venous pressure is elevated, fluid is filtered from the blood into the tissue spaces. This filtration has been identified by the increase in the volume of the congested limb (Mende, 1919; Carrier and Rehberg, 1923; Drury and Jones, 1927); and also by the concentration of protein in the blood which has passed through the congested limb (Rowe, 1916). There is no information, however, concerning the effect in normal human subjects of changing the other equally important factor, namely, the colloid osmotic pressure of the blood.

The association of a low colloid osmotic pressure of the blood with certain forms of edema occurring as a result of disease in man (Krogh, 1922; Hagedorn, Rasmussen and Rehberg, 1922; Govaerts, 1924; Schade and Claussen, 1924; and others), or occurring with experimental hypoproteinemia in dogs (Leiter, 1928) suggests, but does not prove, that the movement of fluid through the capillary wall is related to the colloid osmotic pressure of the blood. The further finding that capillary pressures in the frog, certain rodents, and man (Landis, 1926, 1930) are approximately equivalent to their different blood colloid osmotic pressures is also suggestive, but not conclusive, evidence that the Starling conception probably underlies the mechanism of fluid balance in the mammal.

If fluid balance in man depends upon an approximate balance between capillary pressure and the colloid osmotic pressure of the blood two things must follow. In the first place, as mentioned by Krogh (1929), a relatively small elevation of venous pressure must suffice to cause fluid to accumulate in the tissue spaces, so that the erect human being is constantly near to edema. In the second place, with any given capillary pressure, a rise in the colloid osmotic pressure of the blood must be accompanied by a fall in the rate of filtration.

\footnotetext{
${ }^{1}$ Fellow of the John Simon Guggenheim Memorial Foundation.

2 Sarah Berliner Fellow of the American Association of University Women, 1930-1931.
} 
These two points have been investigated in normal human subjects by two plethysmographic methods of determining arm volume. The results indicate that fluid begins to accumulate in the tissue spaces at venous pressures of $17 \mathrm{~cm}$. water or more, and that at a given venous pressure a rise of the colloid osmotic pressure of the blood is associated with a decrease in the rate at which fluid filters through the capillary wall.

\section{The measurement of fluid filtration by means of the ordinary plethysmograph}

The relation between venous pressure and the rate at which fluid is filtered through the capillary wall was first studied by means of an adaptation of the plethysmograph described by Lewis and Grant (1925). The method and the results obtained with it will be described only in briefest outline since, in spite of careful selection of subjects, it was found that spontaneous variations in arm volume precluded the use of this method for quantitative measurements of the very small amounts of fluid accumulating in the tissues during short periods of slight or moderate venous congestion. The results, inconstant though they are, merit a brief description since they provide qualitative support to certain conclusions reached by another method.

The subjects, 3 women and 1 man, were healthy adults with normal blood pressure, selected from a group of 19 because they showed the smallest spontaneous changes in arm volume when plethysmographic records were made over a period of an hour or more. During an observation the subject reclined with the elbow and hand supported and fixed by sandbags so that the upper surface of the forearm was level with the manubrium sterni. On each forearm was placed a plethysmograph $15 \mathrm{~cm}$. long, the ends of which were closed by means of rubber diaphragms which were accurately fitted to the arm to form an airtight joint without raising venous pressure above $10 \mathrm{~cm}$. water (Fig. 1, $a$ ). Each plethysmograph was connected with a small spirometer of the Krogh type, having a total capacity of about $40 \mathrm{cc}$. The whole system was filled with air, and the variations in arm volume were recorded on a slowly moving kymograph by two pens, one writing above the other (Fig. 1). In these records pulse and respiratory waves were barely visible, and did not interfere with the measurement of the volume changes.

In each experiment one arm was used as a control (lower lines, Fig. 1 $a, b, c)$ and, after a rest period of 30 minutes or more, venous pressure in the other arm was raised to $15,20,25,30$ or $40 \mathrm{~cm}$. water for 15 minutes by means of a Riva Rocci armlet, $15 \mathrm{~cm}$. wide. Figure 1 shows records of the volume changes produced by $15 \mathrm{~cm}$. water (Fig. $1, a), 40 \mathrm{~cm}$. water (Fig. 1, b) and $20 \mathrm{~cm}$. water (Fig. 1, c), the last showing also moderately large spontaneous variations in volume even during the period of congestion. The greatest increase in volume, due to filling of veins and distention of minute vessels, occurred before the fifth minute. From the fifth 
to the fifteenth minute the line was approximately straight with a slope depending on the degree of venous congestion.

In such a closed system containing air it was essential that temperature be carefully controlled. This was done in the first place by using one arm as a control, and by measuring the volume change in terms of differ-
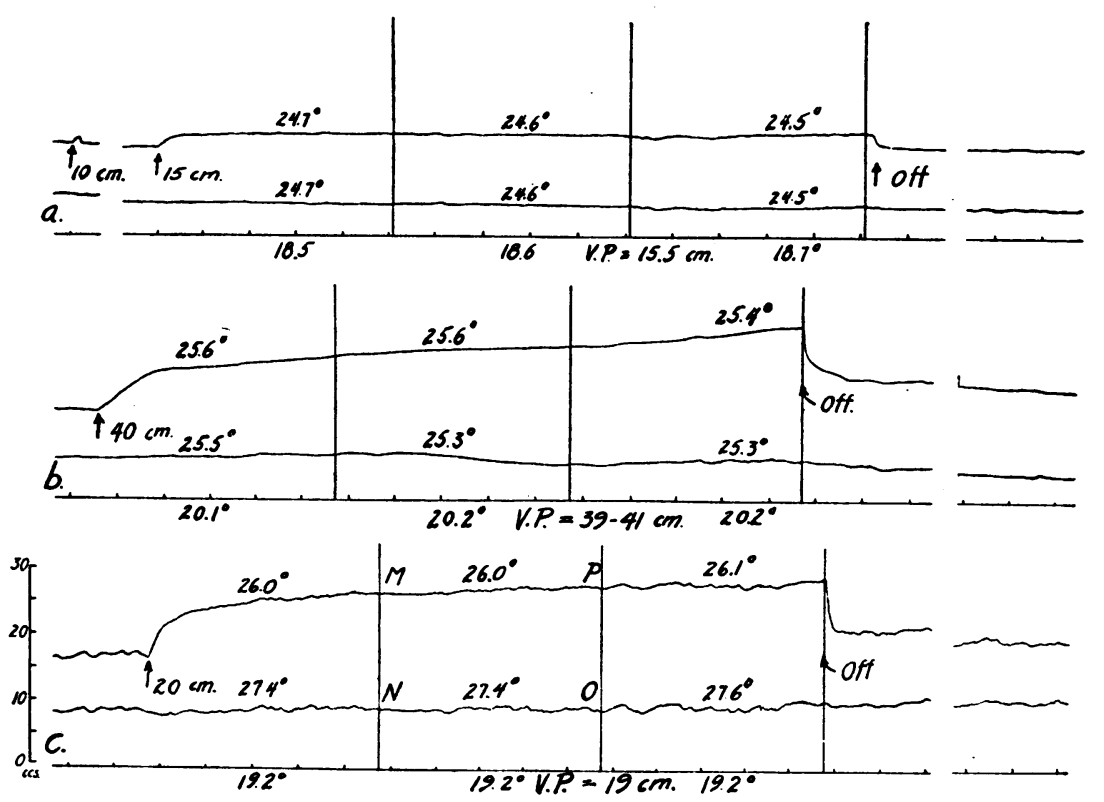

Fig. 1. Records of Change in Arm Volume During 15 Minutes with Venous Pressures of (a) 15 CM., (b) 40 CM., AND (c) 20 CM. Water.

In each record the upper line shows the volume change in the experimental arm, the lower line the volume change in the control arm. The temperature of the air in the plethysmograph is indicated at intervals on each record; room temperature is recorded under the time line. To the left in $(a)$ is shown the increase in volume when venous pressure was raised for a few seconds to $10 \mathrm{~cm}$. water, indicating that venous pressure had previously been less than $10 \mathrm{~cm}$. water. On the right is shown the volume 15 minutes after the release of congestion.

Note: The records, originally written in red, were traced over with black ink to permit marked reduction without loss of clearness. Time, originally marked in .1 minute intervals, is shown only in 1 minute intervals in this figure. To the left is given a composite volume scale made by calibration of both spirometers.

ence between the two records. The temperature of the air within the plethysmograph changed equally in the control and the experimental arm, usually in the downward direction, by an average of $.35^{\circ} \mathrm{C}$. in an experimental period of 30 minutes. Room temperature varied usually only .1 to $.2^{\circ} \mathrm{C}$., very rarely more than $.3^{\circ}$ in the same period. The skin 
temperature of the segment of arm enclosed within the plethysmograph was about $31-32^{\circ} \mathrm{C}$., while the air in the plethysmograph had a temperature between 24.0 and $28.0^{\circ} \mathrm{C}$. Room temperature was between 18 and $20^{\circ}$ except in four instances when it was between 20 and $21^{\circ} \mathrm{C}$. Careful examination of the results indicated that the variability in the findings could not be explained on the basis of temperature changes.

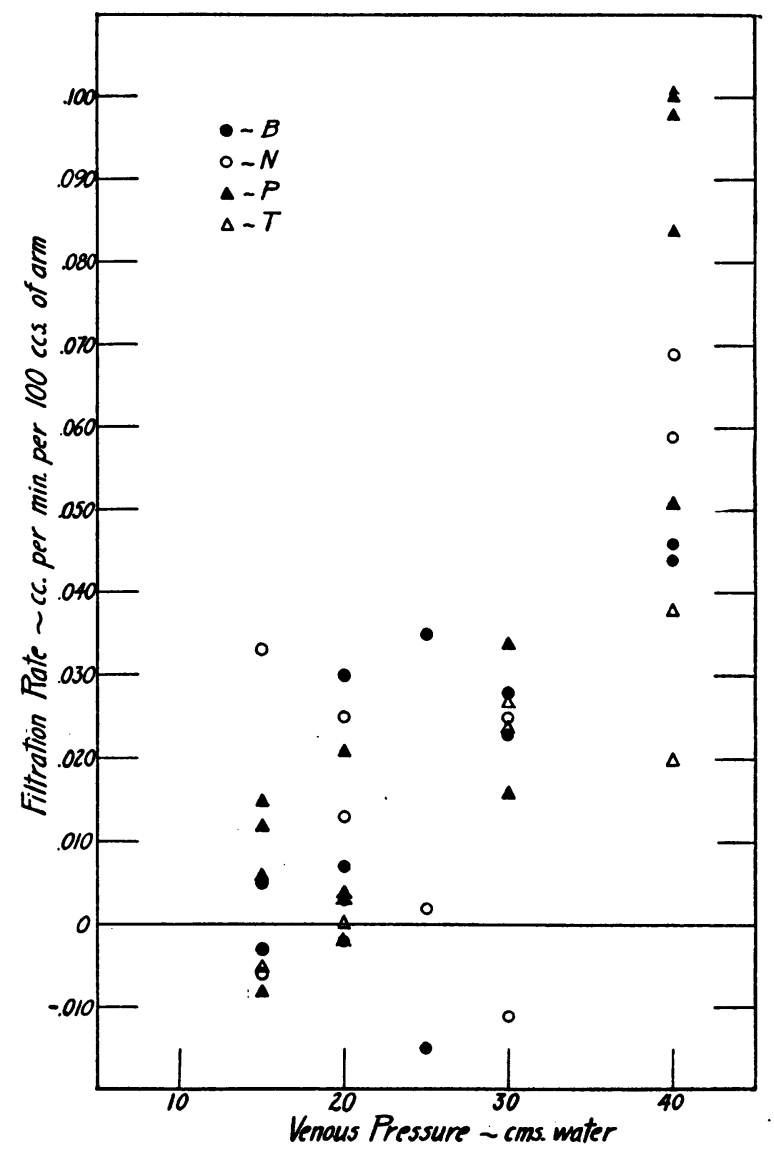

Fig. 2. Relation Between Filtration Rate (cc. per Minute per 100 cc. of Arm) and Venous Pressure (cm. Water) in Four Subjects, as Determined with the Ordinary Plethysmograph.

The computation of filtration rates was frequently complicated by spontaneous variations in volume (Fig. 1,c) which prevented the use of ordinary methods of measurement. Therefore lines were drawn vertically in each record from the time line at the 5 th, 10 th and 15 th minutes. The area $M N O P$ (Fig. 1, c) was measured by planimeter and the figure thus obtained was divided by the linear distance $N O$ to determine the average 
distance in millimeters between the two curves during the period from the fifth to the tenth minutes. The same procedure was used to determine the average distance between the two curves during the period from the tenth to the fifteenth minutes. The difference between these distances, when compared with the calibration figures of the spirometers, indicated the change in volume of the experimental arm compared to the control arm during five minutes' congestion. The volume of the segment of arm within the plethysmograph was measured (as described on page 73) and the apparent rates of fluid movement were computed in terms of cc. of fluid per minute per $100 \mathrm{cc}$. arm. The results have been charted in Fig. 2 to show the relation between the apparent rates of filtration and venous pressure.

The accuracy of this method of measuring the rate at which fluid is filtered into the tissue spaces depends obviously upon the quantitative identity of the spontaneous volume variations in the two arms. Figure 2 shows by the large spread, in sign as well as in magnitude, of the values thus obtained, that the spontaneous variations of volume are not entirely identical in the two arms. This conclusion was verified also by examination of single experiments (Fig. 1, $c$ ). From this it appears evident that a simple plethysmograph is unsuited for the accurate measurement of small amounts of fluid accumulating in the arm at relatively low venous pressures, since the unavoidable vasomotor variations produce spontaneous changes in arm volume which are often greater than the volumes of fluid to be measured (Fig. 1, c).

The results are of value in that they indicate vaguely what was verified definitely by another method. Filtration of fluid may or may not result when venous pressure is elevated to 15 or $20 \mathrm{~cm}$. water; but filtration is clearly evident at a venous pressure of $30 \mathrm{~cm}$. water, becoming still greater at a venous pressure of $40 \mathrm{~cm}$. water.

\section{The pressure plethysmograph}

Quantitative studies of filtration were made by a method which determined the change in volume of the tissues and their contained extravascular fluid, while excluding the contents of the blood vessels. For this purpose pressure was exerted on the surface of the segment of arm within the plethysmograph, to collapse the blood vessels before the final volume was measured. Under these conditions the state of contraction or dilatation of the blood vessels did not, within certain limits, interfere with the reasonably accurate measurement of changes in the volume of tissue fluid.

(a) The apparatus. The plethysmograph, shown in Fig. 3, was made of sheet metal $(P), .5 \mathrm{~mm}$. in thickness, in the form of a truncated cone, having a length of $15 \mathrm{~cm}$. Two sizes were used, the smaller with end diameters of 9 and $10 \mathrm{~cm}$., the larger with end diameters of 10 and $11 \mathrm{~cm}$. A sleeve $(S)$ of thin rubber $(.25 \mathrm{~mm}$. thick), $33 \mathrm{~cm}$. long, 9 and $10 \mathrm{~cm}$. in 
diameter at the ends, was placed inside the metal case and the ends were everted and attached firmly $\left(S^{\prime}\right)$ to the ends of the plethysmograph, by means of cement to ensure a water tight junction. When collapsed the the folds of the inner bag extended about $3 \mathrm{~cm}$. beyond the ends of the metal sleeve, and when filled with water under pressure, the surplus rubber lay against the surface of the arm in a series of folds $(F)$. The ends of the plethysmograph were closed by diaphragms $(D)$ of heavier rubber, $1.0 \mathrm{~mm}$. in thickness. Each diaphragm was cut from rubber obtained in the form of a truncated cone $15 \mathrm{~cm}$. long, 5 and $9.5 \mathrm{~cm}$. in diameter at the ends. The segments were accurately fitted to the arm so that the diaphragms, while tightly stretched over the ends of the metal sleeve, were in gentle contact with the skin of the arm over a distance of 1.5 to $2.0 \mathrm{~cm}$.

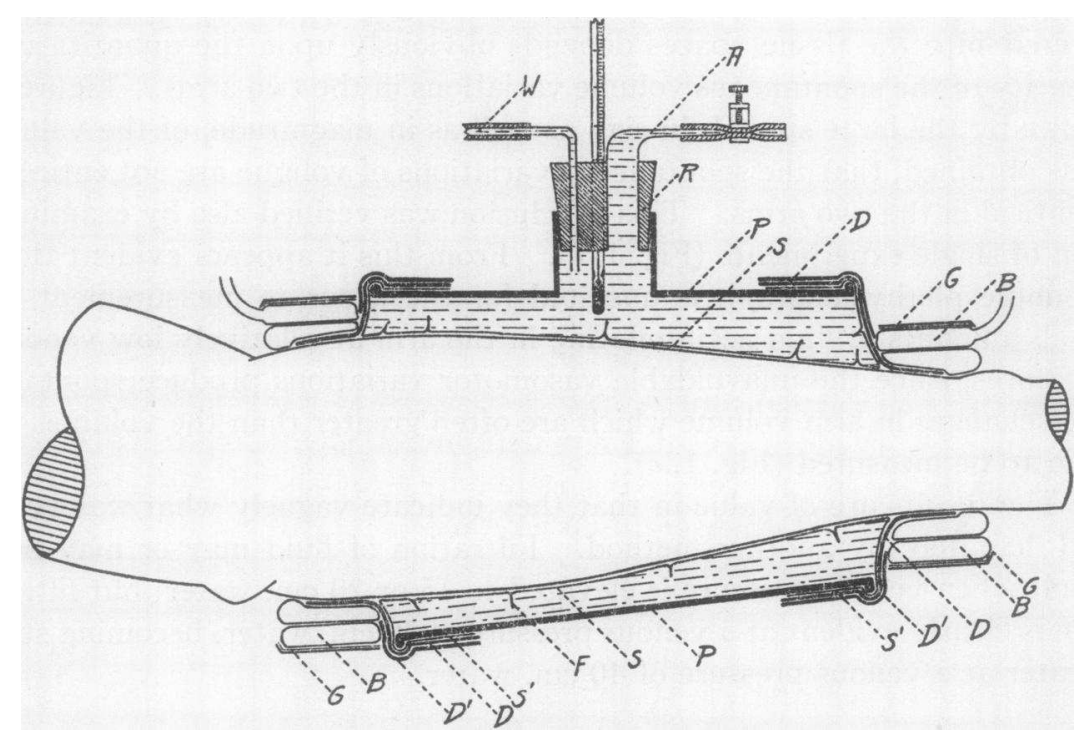

Fig. 3. Diagram of the Pressure Plethysmograph.

For description see text.

To make the ends less distensible a second partial diaphragm of rubber $\left(D^{\prime}\right)$ was arranged to extend half way between the metal sleeve and the skin.

Two rubber bags, $60 \mathrm{~cm}$. long and $3.5 \mathrm{~cm}$. wide, were wound $(B) 2$ or 3 times around the arm above and below the plethysmograph over the skin and the outer portion of the diaphragms. Each bag was held against the arm by several loose turns of gauze bandage $(G)$ so that the inner suface of the rubber bag was in immediate contact with both the diaphragms and the skin. Both bags were connected with a compressed air supply of $55 \mathrm{~cm}$. water pressure, so that, before the pressure inside the plethysmograph was raised, they might be inflated to prevent the thin inner bag from being pushed out between the diaphragms and the skin. 
The large opening in the top of the plethysmograph was closed by a rubber stopper $(R)$ which held one large glass tube $(A)$ to catch any bubbles of air left within the bag, and one small glass tube $(W)$ through which water moved from the plethysmograph to the burette in which volume change was measured. A thermometer inserted into the stopper indicated the temperature of the water surrounding the arm. The movement of 40 to $60 \mathrm{cc}$. of water into and out of the plethysmograph during each volume determination provided adequate mixing. Temperature was measured in a few observations by 2 thermal junctions, one above and the other below the arm, without detecting any significant error in the simpler method. The metal surface of the plethysmograph was covered with cotton wool to diminish heat loss.

The plethysmograph was connected, by pressure tubing running from $W$ (Fig. 3), to the lower end of a $100 \mathrm{cc}$. burette with $.2 \mathrm{cc}$. graduations. The upper end of the burette was connected to a compressed air supply by means of which a pressure of $55 \mathrm{~cm}$. water could be exerted on the contents of the burette, and through $W$ to the inside of the plethysmograph.

Venous congestion was produced by inflating a cuff, $50 \mathrm{~cm}$. long and $15 \mathrm{~cm}$. wide, which encircled the upper arm just above the elbow. To obstruct arterial inflow to the arm (except through the bone) a second cuff, $7 \mathrm{~cm}$. wide and $55 \mathrm{~cm}$. long, was placed just below the axilla. This latter cuff was inflated rapidly from a reservoir to a pressure of $240 \mathrm{~mm}$. $\mathrm{Hg}$ or more. Venous pressure was determined in the veins of the hand both before and during venous congestion by a capsular method described elsewhere (Krogh, Turner and Landis, 1932).

The subjects in all but one series of observations were recumbent with the hand and elbow placed on sandbags so that the plethysmograph was supported only by the forearm. The upper surface of the forearm was level with the manubrium sterni; the arm was abducted to about $30^{\circ}$ at the shoulder, and the elbow was slightly flexed. To avoid movement and the resulting changes in the relation between the arm and the plethysmograph the distal portion of the hand was weighted with sandbags, leaving on the dorsum of the hand only enough room for the venous pressure capsule. It was essential that the subject be absolutely still if reliable readings were to be obtained, and every effort was made to have the subject entirely comfortable before an experiment was begun. The observations in this series were made exclusively on two subjects, one of whom (E. L.) habitually showed large spontaneous changes in arm volume when measured by the ordinary plethysmograph. Blood pressure in both subjects was within the normal range.

At the beginning of an experiment the inner bag of the plethysmograph was arranged so that the extra folds of rubber were collected at the ends of the plethysmograph. The instrument was then slipped on 
the forearm until it reached the position shown in Fig. 3. A short piece of rubber pressure tubing, $4 \mathrm{~mm}$. in outside diameter, with many perforations along its length, was placed between the lateral surface of the forearm and the inner bag, so that it ran completely through the plethysmograph while its ends projected beyond the two diaphragms. Thus any air caught between the inner bag and the skin could escape by this channel when water flowed into the plethysmograph.

To keep the plethysmograph from slipping down the forearm toward the wrist the proximal rubber diaphragm was attached to the skin distal to the elbow joint by means of several short pieces of wide surgeon's plaster. The two external rubber bags were then wrapped loosely about the diaphragms above and below the plethysmograph as shown in Fig. 3 .

Water at a temperature of $34^{\circ} \mathrm{C}$. was poured into the burette and from there entered through $W$ into the inner bag of the plethysmograph, which gradually filled the space around the arm and finally pushed the thin rubber in folds against the skin and the diaphragms. As the water distended the bag the plethysmograph was shaken vigorously to dislodge the air not only from the inner surface of the bag but also from the space between the bag and the skin. The former collection of air was removed through $A$ (Fig. 3), the latter collection found its way under the diaphragms along the rubber tube, which was left between the inner bag and the skin throughout the experiment. The burette was filled approximately to the $20 \mathrm{cc}$. mark and the top of the burette was connected with a tube leading to the compressed air supply.

The forearm is conical in shape and when the pressure in the plethysmograph was raised the whole apparatus tended to slip downward until it was retained by the adhesive tape connecting the upper diaphragm and the skin. In order to settle the apparatus in this final position as rapidly as possible the pressure in the plethysmograph was raised and lowered rapidly and the circulation was cut off several times before the first determination of volume. This diminished the time required for obtaining the series of constant readings which must necessarily precede the measurement of the volume change produced by experimental procedures.

The surface of the water in the burette was always kept level with the upper surface of the plethysmograph. The amount of water in the burette-plethysmograph system was the same through each experiment, so that a decrease in the volume of the arm caused the surface of the water in the burette to fall below the level chosen as the point of reference. The burette was then raised to restore the water to its original level and, pressure being thus constant, the volume change could be read by comparing the volumes indicated on the burette. With a fall in arm volume therefore the burette reading became higher, with a rise in arm volume the burette reading became lower, by an amount equal to the change in arm volume. With normal circulation the spontaneous changes in arm vol- 
ume amounted usually to between 1 and 3 cc., comparing favorably with the spontaneous variations observed with the ordinary plethysmograph.

Venous pressure was measured at this time and was ordinarily between 12 and $14 \mathrm{~cm}$. water in the hand below the plethysmograph. If the venous pressure was over $15 \mathrm{~cm}$. water the diaphragms and cuffs were refitted and adjusted until a venous pressure less than $15 \mathrm{~cm}$. was observed, in order to be certain the filtration was not produced by congestion due to the plethysmograph itself.

(b) The determination of "reduced arm volume." The term "reduced arm volume" will be used to designate the volume of the segment of arm in the plethysmograph when the blood vessels were collapsed by the external pressure. "Arm volume" will refer to the volume of the arm segment when the blood vessels were filled. When the pressure was released between the determinations of "reduced arm volume" the apparatus recorded changes in "arm volume" as an ordinary plethysmograph would have done.

In each determination of reduced arm volume the two small external bags were first inflated with a pressure of $55 \mathrm{~cm}$. water $(A$, Fig. 4). From 3 to 5 seconds later $(B$, Fig. 4$)$ the same pressure was applied to the contents of the burette. Water left the burette rapidly, but the burette was raised in its holder so that the surface of the water was always kept level with the upper surface of the plethysmograph. From 30 to $45 \mathrm{cc}$. of water left the burette in the first 10 to 15 seconds, due in part to removal of blood from the arm and in part to bulging of the diaphragms under the internal pressure. Circulation was not stopped at this time in order that the greater part of the blood expressed from the forearm might be carried away through the open veins. The brachial artery and vein were compressed about 25 seconds $(C$, Fig. 4$)$ after the inflation of the external bags, by raising the pressure in the upper, narrow armlet to $240 \mathrm{~mm}$. $\mathrm{Hg}$ or more. The residual blood could then be expressed from all the blood vessels within the plethysmograph, including arteries and arterioles, by the external pressure of $55 \mathrm{~cm}$. water. This relatively small volume of blood was accommodated by the veins situated in the segment of the arm between the lower border of the occluding armlet and the upper border of the plethysmograph.

The pressure applied to the surface of the segment of arm within the plethysmograph must be high enough to express almost all of the blood within a few minutes, and yet be as low as possible to avoid expressing tissue fluid from the same segment of arm. It was found that $55 \mathrm{~cm}$. of water was the most suitable pressure in this regard since it removed the blood in the course of 3 to 6 minutes.

With this pressure, as shown in Fig. 4, the change in volume in the first minute usually exceeded $40 \mathrm{cc}$, but in the second minute was reduced to between 2 and $4 \mathrm{cc}$., depending on the size of the arm and, as will be 
shown later, on the state of the vessels in the arm. After the second minute, readings of volume were made every 30 seconds, the change in volume in each period becoming steadily less until after the 4 th or 5 th minute it was only .2 to $.15 \mathrm{cc}$. per 30 seconds. The volume continued to decrease quite constantly at this rate even when readings were continued for a total of 10 minutes.

In the usual determinations the readings were continued, as shown in Fig. 4, until in each of 2 successive 30 second periods the volume changed .2 cc. or less. This point was reached after the circulation had been stopped for a period of 3.5 to 6 minutes, or, more rarely with a larger arm,

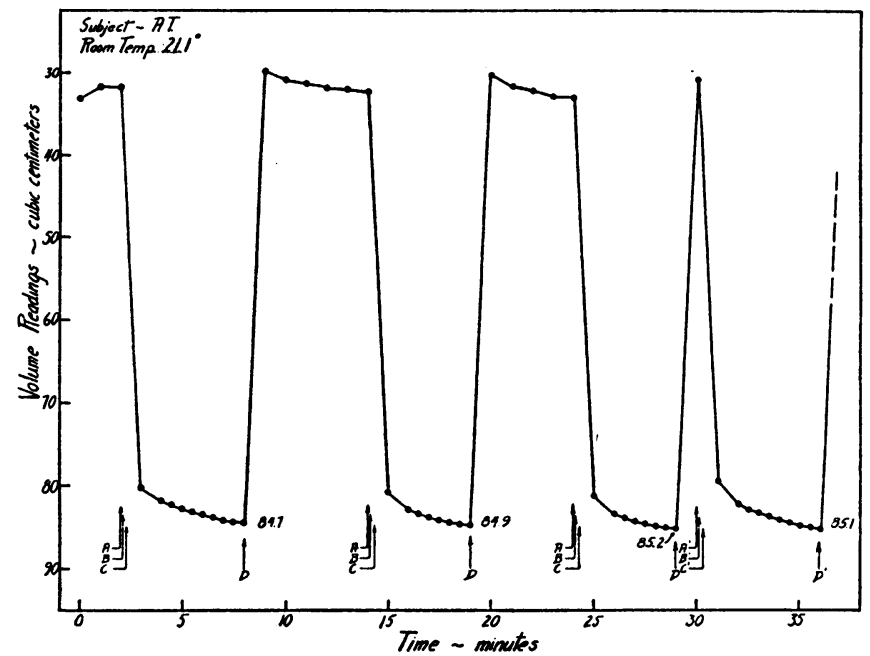

Fig. 4. Chart Showing Burette Readings Between and During Determinations of Reduced Arm Volume by Means of the Pressure Plethysmograph.

The first three determinations were made during normal resting circulation. The last determination was begun during the period of reactive hyperemia which followed the last control estimation. For full description see text.

7 minutes. Readings were never continued beyond 7 minutes because an excessively long anoxemia might modify the permeability of the capillary wall. There was some indication that this occurred if circulation was cut off for 10 minutes or longer; a period of 7 minutes was therefore regarded as the extreme limit of complete safety.

The reading obtained at the end of one minute of minimal change in volume ( 2 cc. per 30 seconds) was recorded for comparison with other readings made under the same conditions in later determinations. In Fig. 4 the burette reading at the end of the first determination was 84.7 cc. Pressure was released ( $D$, Fig. 4 ) first from the inner bag, a few seconds later from the external bags, and finally about 10 to 15 seconds later from the armlet. Circulation was resumed, and, due to reactive hyper- 
emia, the arm volume one minute later was $2.5 \mathrm{cc}$. higher than at the beginning of the determination.

A period at least as long as the preceding occlusion was allowed to elapse before the next determination; this seemed sufficient since Lewis and Grant (1925) found that reactive hyperemia lasted not more than $3 / 4$ as long as the occlusion period which produced it. A second determination made in the experiment shown in Fig. 4 yielded a final reading of $85.0 \mathrm{cc}$., and a third, after a similar recovery period, $85.2 \mathrm{cc}$. Reduced arm volume therefore varied in these three control readings through a range of $.5 \mathrm{cc}$.

At the beginning of each experiment determinations were made in this way at intervals of 10 to 15 minutes until 3 consecutive readings were obtained with a total variation of $.5 \mathrm{cc}$. or less. This occurred frequently as in Fig. 4 in the first 3 determinations, but more often the first 2 or 3 readings showed a greater variation usually in the direction of an apparent decrease in arm volume. This may have been due to the removal of small amounts of tissue fluid from the arm, or to slight change in the relation between the plethysmograph and the arm. The final agreement, however, was at times as close as .1 to $.3 \mathrm{cc}$., with variations lying in a haphazard way both above and below the average value, as shown in the control period in Fig. 5. In the experiments where total variation could not be reduced to less than $.5 \mathrm{cc}$. after a number of trials the observations were discontinued, usually with the discovery of a hidden leak in the inner bag, or of an unequal distribution of the folds in the inner bag.

Having obtained three control readings within the limits mentioned above, venous congestion was applied for a given period of time. One minute after the release of the congestion reduced arm volume was determined again. The difference between this last reading and the average of the 3 control readings indicated the volume of "tissue fluid" which had accumulated during the period of congestion and still remained in the tissues. It is likely that the lymph vessels were emptied by the external pressure in the same way as the blood vessels, so that the increase in reduced arm volume represented the volume of "tissue fluid."

At the end of the experiment the apparatus was removed and the approximate volume of the segment of arm enclosed by the plethysmograph was determined. The upper and lower boundaries of the inner bag were clearly marked on the skin since the folds of rubber produced elevations in the skin not unlike minute linear wheals. The circumference of the arm was measured at both boundaries and from the average circumference and the length of the arm segment the volume could be computed. This method of measurement was only approximate but nevertheless agreed fairly well with determinations of volume made by displacement of water. Moreover examination of the data below will show that other unavoidable variations made a more exact measurement unnecessary. In sub- 
ject $A$. T. the volume of forearm within the plethysmograph was between 445 and 540 cc., in subject E. L. between 580 and 690 cc., the exact figure depending upon the nearness of the plethysmograph to the elbow.

The rate of filtration at a given venous pressure was computed by dividing the increase in reduced arm volume by the duration of the congestion and by the volume of the arm segment. The filtration rates are expressed in terms of cc. of fluid filtered per minute per $100 \mathrm{cc}$. of arm.

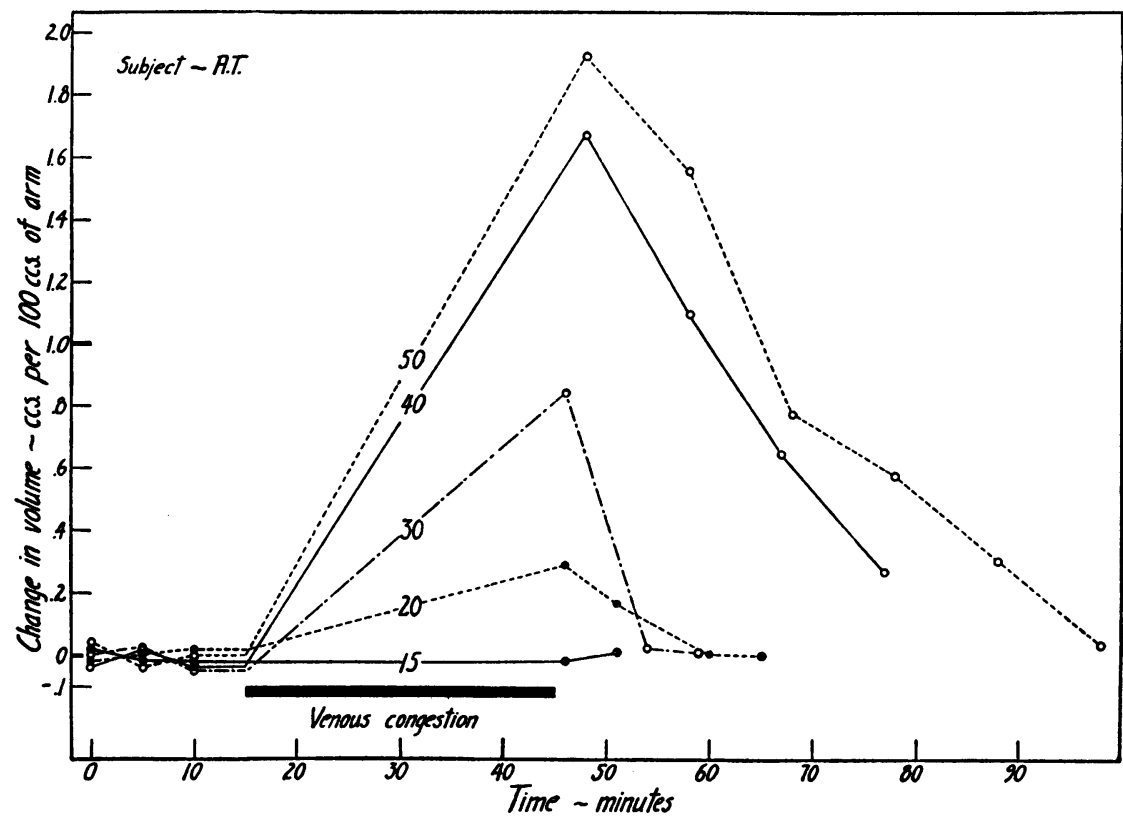

Fig. 5. Chart Showing the Accumulation of Tissue Fluid (cc. Per 100 cc. of Arm) Produced by Venous Congestion of 15, 20, 30, 40 and 50 cm. Water Pressure Applied over a Period of 30 Minutes.

To the right is shown the removal of the tissue fluid after release of the venous congestion.

Each dot or circle represents a determination of reduced arm volume, requiring from 4 to 5 minutes' stoppage of circulation.

Where volume changes alone are mentioned they are recorded in terms of cc. of fluid per $100 \mathrm{cc}$. of arm.

The further details of method apply only to single groups of experiments and will be taken up under the appropriate headings.

\section{Observations}

(a) Hyperemia and reduced arm volume. The usefulness of the pressure plethysmograph depended upon the extent to which the reduced arm volumes were independent of vascular tone. This was tested by comparing the reduced arm volumes determined during normal circulation with those determined during reactive hyperemia. Figure 4 shows 
one of these experiments with 3 control determinations of reduced arm volume, each begun during normal circulation; and a fourth determination which was begun in the middle of the reactive hyperemia which followed the last control observations. Arm volume, due to vascular dilatation, was $2.4 \mathrm{cc}$. higher, but reduced arm volume was within $0.1 \mathrm{cc}$. of the last control reading.

In a group of six similar experiments arm volume was from 1.3 to 7.0 cc. greater in the hyperemic period which followed the complete occlusion of circulation for 5 to 10 minutes. Reduced arm volumes were unchanged or slightly less in 3 instances, and greater by only $0.1,0.3$ and $0.4 \mathrm{cc}$. in the other three. It may be noted also in Fig. 4 that when the determination of reduced arm volume was made during hyperemia the change in volume during the first few minutes was greater, and the time required for the volume change to reach the rate of $.2 \mathrm{cc}$. per 30 seconds was longer. This was to be expected since a greater mass of blood must be expressed when the vessels are dilated.

Since the reduced arm volume was independent of vascular dilatation of the magnitude described above, it seemed safe to assume that the ordinary spontaneous changes in vascular tone had no significant effect on reduced arm volume. This, in fact, was frequently observed in single experiments; arm volumes of ten varied through a range of $3 \mathrm{cc}$. or more during the period when control readings were made, while the reduced volumes differed only by .1 to $.3 \mathrm{cc}$.

(b) The relation between filtration rate and venous pressure. The minimal venous pressure required to produce filtration, and the change in the filtration rate with various degrees of venous congestion were studied in both subjects. Room temperature was between $20.0^{\circ}$ and $21.5^{\circ} \mathrm{C}$. with the exception of one experiment in which it was $18.1^{\circ}$. The temperature of the water in the plethysmograph was between $26.8^{\circ}$ and $30.5^{\circ} \mathrm{C}$.

In the preliminary control period (Fig. 5, Protocol 1) venous pressure was determined, and three or more readings of volume were made in order to demonstrate that arm volume was not changing significantly. Five minutes after the end of the last control reading the wide armlet was inflated to the desired pressure. The effectiveness of the lesser degrees of congestion ( 12.5 to $30 \mathrm{~cm}$. water) was verified by measuring venous pressure in the hand (Protocol 1). The venous congestion was continued for 30 minutes and then released. One minute was allowed for the escape of the blood temporarily accumulated in the arm by the congestion; as shown by the ordinary plethysmograph records (Fig. 1) this escape is practically complete in $\mathbf{4 5}$ seconds or less. At the end of this minute a determination of volume was begun, and later at intervals the determinations were repeated to follow the subsequent removal of the fluid.

Figure 5 shows the change in reduced arm volume, expressed in cc. per $100 \mathrm{cc}$. of arm, shown by subject A. T. during and after a 30 minute 
CAPILLARY WALL

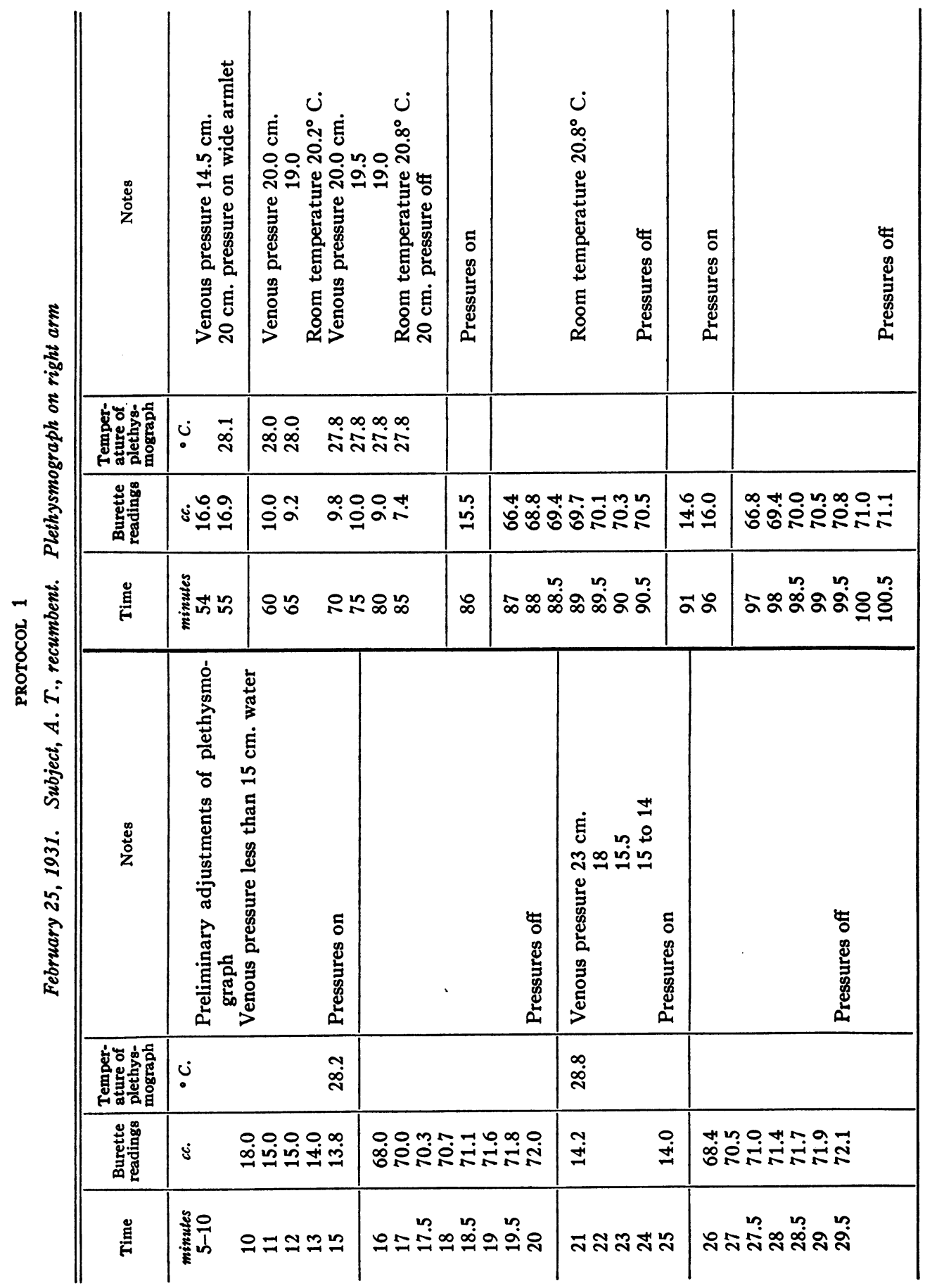


A. KROGH, E. M. LANDIS AND A. H. TURNER

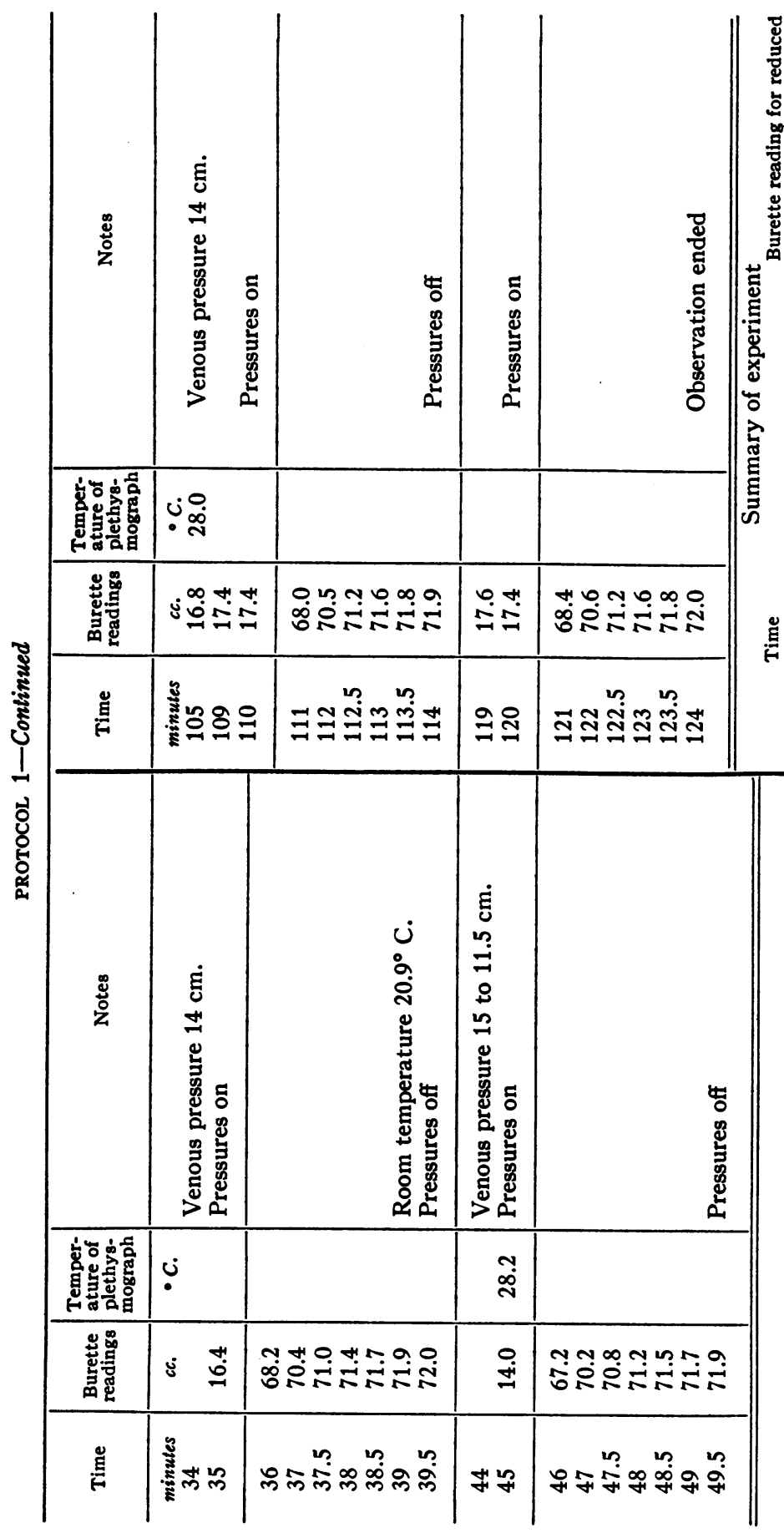

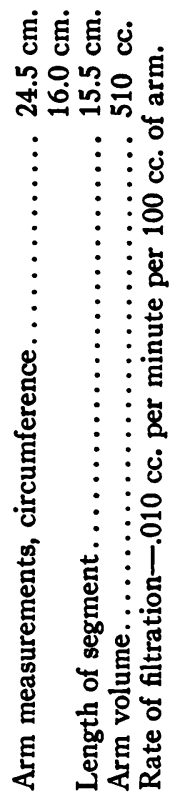


period of venous congestion with $15,20,30,40$ and $50 \mathrm{~cm}$. water pressure. A circle or dot represents a determination of reduced arm volume, each of which required the complete stoppage of circulation during 4 or 5 minutes. The lines therefore represent the change in the volume of tissue fluid in relation to the time when the blood was actually flowing through the arm. This period alone is of significance in relation to filtration or absorption.

During the control period the maximum variation in reduced arm volume was slightly less than $.1 \mathrm{cc}$. per $100 \mathrm{cc}$. of arm. With a venous pressure of $15 \mathrm{~cm}$. water there was no demonstrable change in reduced arm volume, but with a venous pressure of $20 \mathrm{~cm}$. it had increased at the end of 30 minutes by over $.2 \mathrm{cc}$. per $100 \mathrm{cc}$. This increase in reduced arm volume was greater with higher venous pressures, amounting to almost $2 \mathrm{cc}$. per $100 \mathrm{cc}$. after 30 minutes' congestion with $50 \mathrm{~cm}$. water pressure. The details of an experiment with a venous pressure of $20 \mathrm{~cm}$. water are given in Protocol 1.

The fact that the higher degrees of congestion produced a greater distention of the vessels and a correspondingly greater accumulation of blood in the arm made it necessary to determine whether this factor in itself affected the reduced volume measurements. It was conceivable that reduced arm volume might be increased after congestion merely because more blood was imprisoned in the arm prior to the determination. Table 1, however, shows clearly that this was not the case. In a series of

TABLE 1

Effect of duration of congestion on arm volume and reduced arm volume

\begin{tabular}{|c|c|c|c|c|c|c|c|}
\hline \multirow{2}{*}{ Subject } & \multirow{2}{*}{$\begin{array}{l}\text { Venous } \\
\text { pressure }\end{array}$} & \multirow{2}{*}{$\begin{array}{l}\text { Duration of } \\
\text { congestion }\end{array}$} & \multirow{2}{*}{$\underset{\text { volume }}{\text { Arm }}$} & \multirow{2}{*}{$\begin{array}{l}\text { Temperature of } \\
\text { plethysmograph }\end{array}$} & \multicolumn{2}{|c|}{$\begin{array}{l}\text { Change in volume } \\
\text { during congestion }\end{array}$} & \multirow{2}{*}{$\begin{array}{l}\text { Rate of } \\
\text { filtration }\end{array}$} \\
\hline & & & & & $\begin{array}{c}\text { Arm } \\
\text { volume }\end{array}$ & $\begin{array}{c}\text { Reduced arm } \\
\text { volume }\end{array}$ & \\
\hline & $\underset{\text { water }}{c m}$ & minutes & $c c$. & ${ }^{\circ} C$. & $c c$. & $c c$. & $\begin{array}{l}\text { cc. per } \\
\text { minule per } \\
100 \text { cc. }\end{array}$ \\
\hline A. T.... & 50 & $\begin{array}{r}5 \\
10 \\
20 \\
30\end{array}$ & $\begin{array}{l}445 \\
505 \\
530 \\
520\end{array}$ & $\begin{array}{l}27.1 \\
27.5 \\
26.8 \\
27.6\end{array}$ & $\begin{array}{l}15 \\
28 \\
23 \\
27\end{array}$ & $\begin{array}{r}1.4 \\
4.7 \\
6.6 \\
11.6\end{array}$ & $\begin{array}{l}.063 \\
.093 \\
.064 \\
.075\end{array}$ \\
\hline E. L.... & 50 & $\begin{array}{r}5 \\
10 \\
20 \\
30\end{array}$ & $\begin{array}{l}640 \\
680 \\
690 \\
650\end{array}$ & $\begin{array}{l}29.4 \\
29.4 \\
29.5 \\
30.5\end{array}$ & $\begin{array}{l}31 \\
31 \\
42 \\
37\end{array}$ & $\begin{array}{r}2.9 \\
5.4 \\
12.3 \\
12.9\end{array}$ & $\begin{array}{l}.091 \\
.079 \\
.089 \\
.066\end{array}$ \\
\hline
\end{tabular}

4 separate experiments on each subject venous pressure was elevated to $50 \mathrm{~cm}$. water for 5, 10, 20 and 30 minutes. Arm volume was observed during the period of congestion, and the difference between the volume immediately before the congestion was begun and the volume at the 
end of the congestion period represents the sum of $(a)$ the volume of blood retained in the vessels and $(b)$ the volume of the fluid which has been filtered into the tissue spaces. For comparison with this figure, the change in reduced arm volume produced by the same periods of congestion are also given in Table 1 . It is evident that the change in arm volume had no constant relation to the duration of congestion, while the change in reduced arm volume clearly depended on the duration of congestion. From this comparison it is safe to state that the increase in reduced arm volume is not directly related to the volume of blood contained in the congested vessels, but is due primarily to the accumulation of tissue fluid.

The rates of filtration in a larger series of observations on both subjects have been computed and charted in Fig. 6 to show the relation between

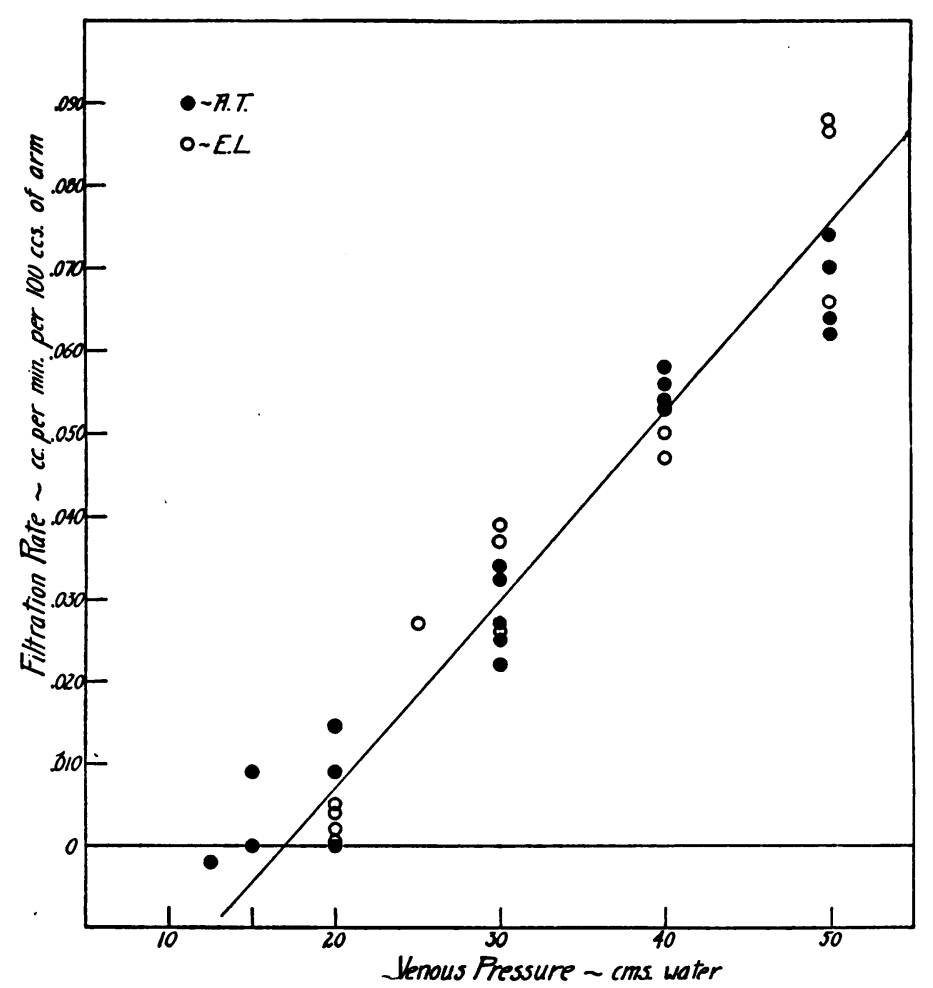

Fig. 6. Chart Showing Relation Between Rate of Fluid Filtration (cC. Per Minute per 100 cC. of Arm) and Venous Pressure (CM. WATER).

venous pressure and filtration rate. This chart includes experiments in which the congestion periods were between 15 and 30 minutes in duration.

Each subject showed in one experiment no filtration with a venous pressure of $20 \mathrm{~cm}$. water, but more of ten filtration was observed at this 
pressure. Filtration was always present at venous pressures of $30 \mathrm{~cm}$. or over. This indicates that there is a definite though small margin of safety against the production of edema in man, in that under the temperature conditions existing in these observations venous pressure could be elevated to $15 \mathrm{~cm}$. or even to $20 \mathrm{~cm}$. water before fluid accumulated in the tissue spaces.

It is difficult to explain satisfactorily the variations in the rate of filtration observed at any one venous pressure. Drury and Jones (1927) have shown that the rate of filtration during venous congestion increases as the temperature of the arm is raised. In the experiments charted in Fig. 6 the average temperatures of the arm during the filtration period varied less than 4 degrees, and most of the determinations were made within a range of 2 degrees. There is some indication that the variability of filtration rate may at times be partly explained by differences in temperature, but there is no general relationship in our data between higher temperature and the higher filtration rates. It is probable that another factor was more important. The filtration rate per $100 \mathrm{cc}$. of arm must be related to the extent of the filtering area in the arm, which must depend upon the number of open capillaries and their diameters. Local factors, temperature among others, were controlled as far as possible, but central variations in vasomotor tone could not be excluded and the variations in filtration rate may well be related to differences in the filtering area produced in this way.

The variations in filtration rate, though distinctly outside the limits of experimental error, were not sufficient to cause any overlap in the values observed at 20,30, 40 and $50 \mathrm{~cm}$. water pressure. As may be seen in Fig. 6 the average point at which filtration begins is apparently $17 \mathrm{~cm}$. water, and above this pressure the rate of filtration is directly proportional to the difference between venous pressure and $17 \mathrm{~cm}$. water. This straight line relationship between venous pressure and filtration rate permits the calculation of the average increase in filtration rate which is produced by an increment of $1 \mathrm{~cm}$. water pressure, above $17 \mathrm{~cm}$. water. This, determined from the slope of the line in Fig. 6, amounts to $.0023 \mathrm{cc}$. per minute per $100 \mathrm{cc}$. of arm per cm. water pressure. This will be compared later with a similar figure computed for the reduction in filtration rate with increase in the osmotic pressure of the plasma proteins.

(c) The removal of fluid from the tissues of the forearm. Since a venous pressure of $20 \mathrm{~cm}$. water causes an accumulation of fluid in the tissue spaces, the same pressure should prevent the absorption of fluid from the tissue spaces, or even produce further accumulation. The term "removal of fluid" has been used in the heading of this section because it has been impossible to separate definitely the "absorption" of fluid by the capillaries from the "drainage" of fluid by the lymphatic vessels. The measurements of reduced arm volume could demonstrate merely that fluid 
left the arm, not the path it took in leaving. Nevertheless the effect of venous congestion on the process of restoring the normal fluid content of the tissue spaces suggests that absorption is more important with small accumulations and that lymphatic drainage is more important with larger accumulations.

The rate at which fluid was removed from the tissues is indicated in the right hand portion of Fig. 5, where volume readings were continued after the congestion period, until all or nearly all of the fluid had been removed. The individual readings do not provide uniformly smooth curves because of the experimental error in single determinations of relatively small changes in volume, and because the accuracy of the determinations diminished as the subject became fatigued.

The period required for the removal of an accumulation of fluid depended, as would be expected, on the amount of fluid present in the tissues. The larger accumulations, however, were removed at a slightly more rapid rate than the smaller accumulations. This is shown in Table 2 , where the average rate of removal of fluid has been calculated from 14 curves of the type shown in Fig. 5. If more than $.6 \mathrm{cc}$. of fluid per $100 \mathrm{cc}$. of arm was present the fluid was removed at the average rate of $.040 \mathrm{cc}$. per minute per $100 \mathrm{cc}$, with variations ranging from .009 to .078 . If less than $.6 \mathrm{cc}$. of fluid per $100 \mathrm{cc}$. of arm was present the rate of removal was $.026 \mathrm{cc}$. per minute per $100 \mathrm{cc}$., with variations between .012 and .047 . In later observations (Fig. 7) the rates observed in the two subjects were almost identical, though in earlier experiments E. L. showed slower rates and certain irregularities. The latter were probably due to the use of a plethysmograph which fitted the arm too closely.

Knowing the normal rate for the removal of fluid with venous pressures between 12 and $14 \mathrm{~cm}$. of water (Fig. 5), the effect of venous congestion on this process was tested (Fig. 7). With the subject recumbent readings were taken in the usual way during a control period to demonstrate that the volume of the arm was not changing significantly. A pressure of $50 \mathrm{~cm}$. water was applied to the upper arm for $5,10,20$ or 30 minutes in order to produce small and large accumulations of fluid. The amount of fluid in the tissues at the end of the congestion period was determined. Immediately after the circulation was released at the end of this reading, the large armlet was distended by a pressure of 15 $\mathrm{cm}$. water. This degree of congestion was continued for 15 minutes. One minute was allowed to elapse in order that the blood previously imprisoned in the arm might escape. At the end of this minute reduced arm volume was determined again, and followed immediately by a 15 minute period of venous congestion at $20 \mathrm{~cm}$. water pressure. The procedure was repeated for a third period of 15 minutes with congestion of $30 \mathrm{~cm}$. water, after which the reduced arm volume was again measured. Finally, the process of fluid removal was permitted to continue without congestion, while venous pressure was measured at frequent intervals. 
The results of eight experiments of this kind are presented in Fig. 7 which shows that the influence of venous congestion on the removal of fluid is also affected by the amount of the extravascular fluid present. A venous pressure of $15 \mathrm{~cm}$. water conspicuously diminished, but did not entirely stop, the removal of fluid when the amount in the tissues was less than $.6 \mathrm{cc}$. per $100 \mathrm{cc}$. of arm. Above this point $15 \mathrm{~cm}$. pressure had less effect, and with the largest accumulations the rate of removal was in no way different from that observed without congestion.

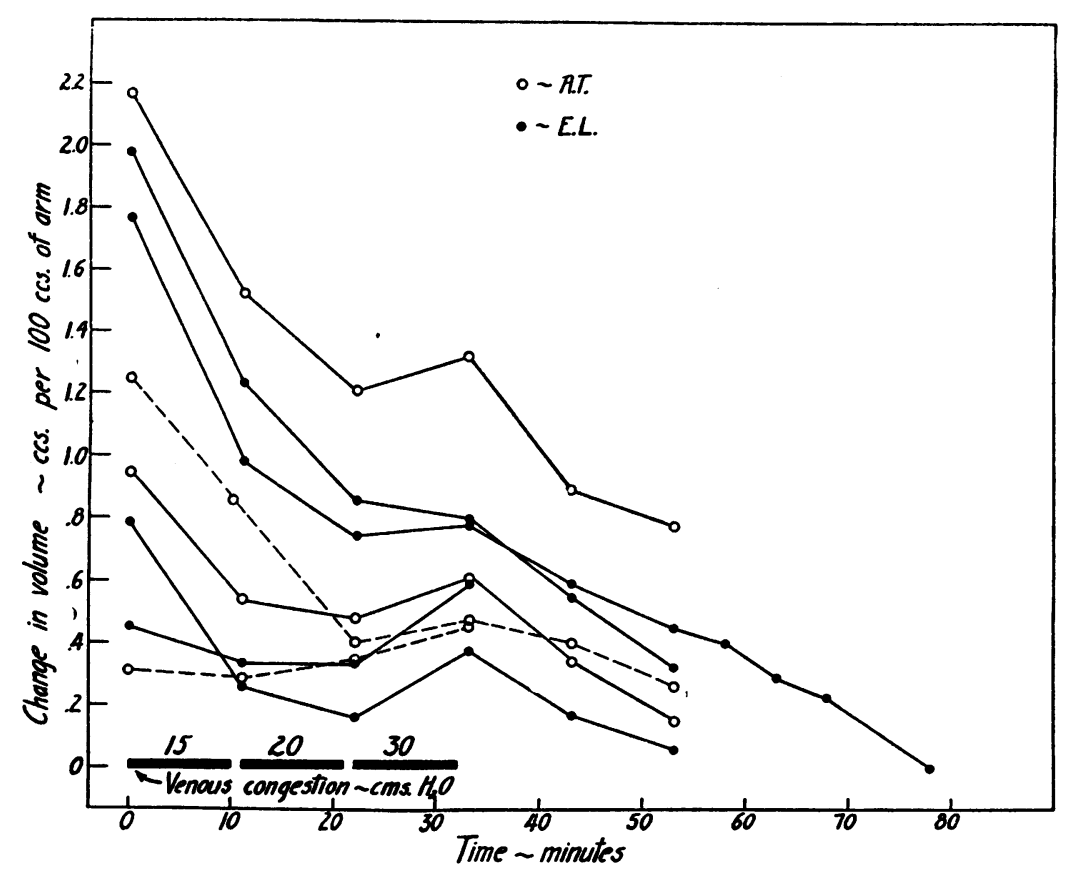

Fig. 7. Chart Showing the Effect of Venous Congestion on the Removal of Tissue Fluid from the Arm.

Each dot or circle represents a determination of reduced arm volume, requiring from 4 to 6 minutes' stoppage of circulation.

A pressure of $20 \mathrm{~cm}$. water diminished the rate of removal of smaller accumulations conspicuously and of the larger accumulations only slightly. A pressure of $30 \mathrm{~cm}$. water produced filtration in all but one experiment in which a very slow removal of fluid was observed.

The average rates at which fluid was removed under these conditions have been calculated from the curves in Fig. 7 and summarized in Table 2. It is obvious that the process of fluid removal was, with small accumulations, modified by 20 , or even by $15 \mathrm{~cm}$. water pressure, which suggests that true absorption through the capillary wall is responsible for the removal of small collections of tissue fluid. 
TABLE 2

Effect of venous congestion on removal of tissue fluid

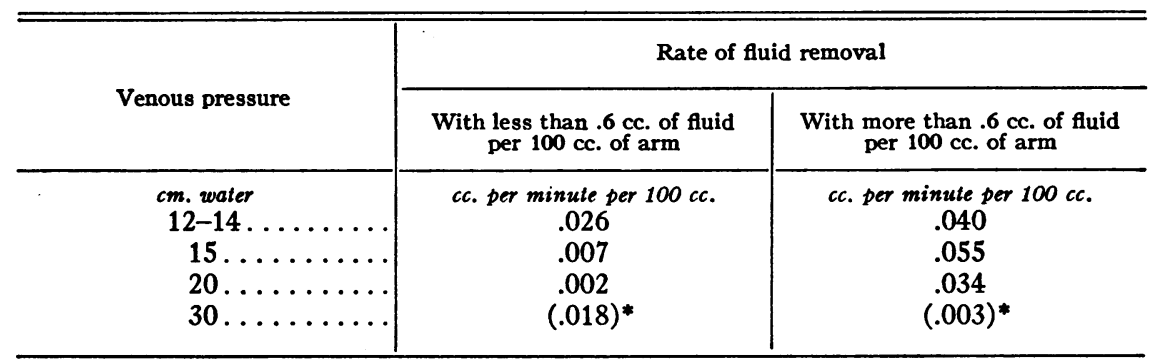

( ) *-Accumulation of fluid instead of removal of fluid.

When the amount of fluid in the arm was greater, however, the effect of each congestion pressure on the rate of removal was conspicuously less. A venous pressure of $30 \mathrm{~cm}$. water increased the volume of tissue fluid at rates from .022 to $.039 \mathrm{cc}$. per minute per $100 \mathrm{cc}$. in a forearm in which no previous filtration had occurred. The highest rate observed with this grade of congestion superimposed on an earlier filtration was $.022 \mathrm{cc}$. per minute per $100 \mathrm{cc}$. The average filtration rate observed with $30 \mathrm{~cm}$. water pressure in the presence of a previous accumulation of fluid was about half that produced in the absence of such an accumulation. Moreover, with very large accumulations of tissue fluid, $30 \mathrm{~cm}$. water was observed to lose completely its power of producing an increase in the volume of tissue fluid. It appears from these observations that the presence of an accumulation of fluid in the tissue spaces reduces the power of the lesser grades of venous congestion to produce a further increase in the volume of tissue fluid. There is some mechanism which facilitates the removal of fluid and which makes further accumulation more difficult. The relation of these findings to tissue turgor and to lymph drainage will be discussed below.

(d) The colloid osmotic pressure of the blood and the rate of fluid filtration during venous congestion. The change from the reclining to the standing position is followed by the filtration of water and diffusible constituents from the blood into the tissues of the lower extremities (Thompson, Thompson and Dailey, 1928; Harrop and Waterfield, 1930) with a consequent increase in the blood protein concentration. The colloid osmotic pressure of the blood may be increased by this procedure by as much as $12 \mathrm{~cm}$. of water, as reported by $\mathrm{Ni}$ and Rehberg (1931), though in their experiments water intake was considerably increased.

In a series of six experiments the colloid osmotic pressure of the blood was elevated by standing, and the rates of filtration into the arm tissues were then determined for comparison with those observed in the same subjects when recumbent. It was found that with a given venous pressure the filtration in the arm of the standing subject was uniformly less. 
Three observations were made on each of the two subjects, with venous congestions of 25,30 and $40 \mathrm{~cm}$. water. The experiments were performed in pairs so that on one day the filtration was determined both in the recumbent and in the standing position, with the single exception of Experiment 2 (Table 3). The salient features of a complete experiment are outlined in Protocol 2. The subjects stood with their backs against

PROTOCOL 2

February 5, 1931. Subject E. L. Plethysmograph on right arm

Time

Remarks

10.00 A.M

Subject began standing against board inclined at $75^{\circ}$. Forearm at level of suprasternal notch

10.30-11.00 A.M.......... Difficulties in adjustment of plethysmograph. Readings of reduced arm volume inconstant

11.15 A.M............. Reduced arm volume $71.6 \mathrm{cc}$.

11.26 A.M............. Reduced arm volume 71.7

11.36 A.M................ Reduced arm volume 71.4 (Average of control readings 71.6)

11.46 A.M. to 12.01 P.M..... Venous congestion of $40 \mathrm{~cm}$. water pressure

12.02 P.M.............. Reduced arm volume $68.7 \mathrm{cc}$. (Volume increased $2.9 \mathrm{cc}$.)

12.15 P.M............... Blood sample (Protein 8.5 per cent, colloid osmotic pressure $43.7 \mathrm{~cm}$. water)

12.16 P.M............ Volume of arm segment 635 cc. Filtration rate .030 cc. per minute per $100 \mathrm{cc}$. of arm. Observation terminated

2.25 P.M............. Subject reclined. Plethysmograph adjusted. Readings of reduced arm volume at first inconstant

2.55 P.M............. Reduced arm volume $84.6 \mathrm{cc}$.

3.05 P.M................ Reduced arm volume 84.9

3.15 P.M.............. Reduced arm volume 85.1 (Average of control readings 84.9)

3.25-3.40 P.M..........Venous congestion of $40 \mathrm{~cm}$. water pressure

3.41 P.M.............. Reduced arm volume $80.6 \mathrm{cc}$. (Volume increased $4.3 \mathrm{cc}$.)

3.55 P.M............... Blood sample (Protein 7.6 per cent, colloid osmotic pressure $38.7 \mathrm{~cm}$. water)

3.56 P.M............ Volume of arm segment $605 \mathrm{cc}$. Filtration rate $.047 \mathrm{cc}$. per minute per $100 \mathrm{cc}$. of arm. Observation terminated

a support inclined at an angle of $75^{\circ}$ to the floor. The hydrostatic and vascular changes in this position are practically identical with those of the completely vertical position (Turner, Newton and Haynes, 1930), while the subjects could stand more quietly and for longer times than would otherwise have been possible. The greater muscular relaxation thus obtained was advantageous not only because it increased the accumulation of fluid in the legs (Harrop and Waterfield, 1930) but also because it permitted more accurate volume determinations. The arm was supported on a high table, with the upper surface of the forearm at the level of the suprasternal notch. The flexion of shoulder and elbow was adjusted to the position of greatest comfort.

While the subject was standing the plethysmograph was filled and adjusted as in the reclining experiments. The burette was raised on its standard so that the surface of the water could be kept level with the 
A. KROGH, E. M. LANDIS AND A. H. TURNER

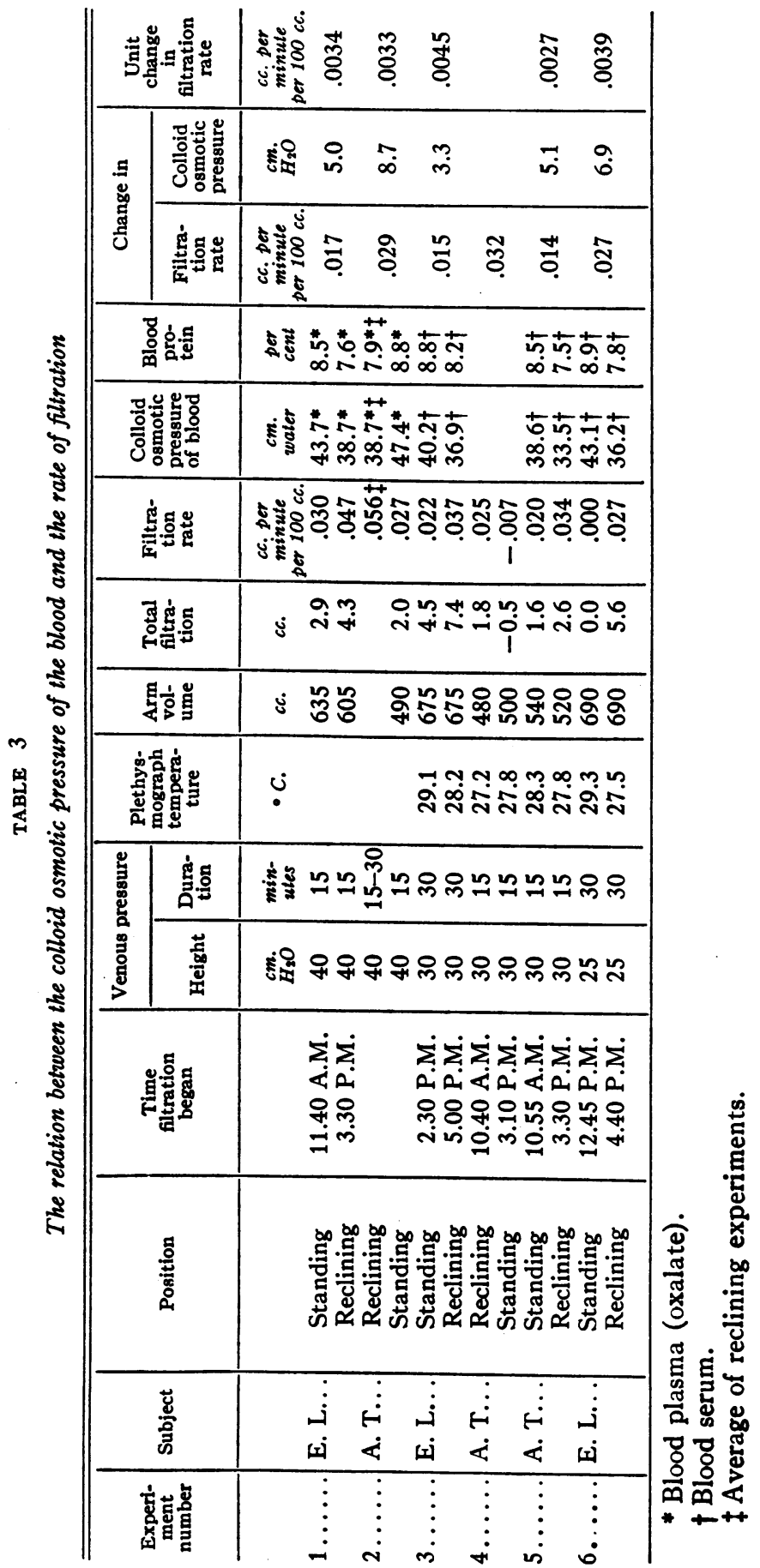


upper surface of the plethysmograph. In the control period readings were taken as usual until the consecutive readings were constant. At the time when venous congestion was begun the subjects had been standing for periods ranging from 53 to 102 minutes. Venous congestion of 25,30 or $40 \mathrm{~cm}$. water was applied for 15 or 30 minutes. One minute after this congestion was released another determination of reduced arm volume was made. As soon as possible after this a blood sample was removed from an antecubital vein, without congestion except for the few seconds required to introduce the needle into the vein. Protein percentage was estimated by the Zeiss Eintauch-Refraktometer, and the colloid osmotic pressure of the blood was determined by the method of Krogh and Nakazawa (1927), using plasma with oxalate in experiments 1 and 2 , and blood serum in the remainder.

The subjects, after a rest period of 1 to 2 hours, reclined and the determination of filtration rate was repeated. A second blood sample was removed after this congestion period and treated in the same way as the first sample. The order of the experiments was arranged so that the reclining observation usually followed the standing observation, which permitted double comparison with the reclining filtration rates. The two experiments were separated by a rest period several times longer than was required to absorb the fluid filtered during the first congestion; yet it was barely possible that even slight filtration several hours before might modify the rate of filtration in the second observation. When the standing observation preceded it was possible to compare standing filtration not only with the control done on the same day, but also with the maximum range of variation in the reclining position, shown in Fig. 6. In addition, however, the order was reversed in experiment 4 (Table 3) without effect on the result.

The six pairs of observations are summarized in Table 3. The filtration rates observed in the standing position were without exception lower than the lowest filtration rates observed in earlier reclining experiments (Fig. 6) on the same subjects. Comparison of the paired observations shows that colloid osmotic pressure was from 3.3 to $8.7 \mathrm{~cm}$. water higher in the standing position, while the rates of filtration were from .014 to $.032 \mathrm{cc}$. per minute per $100 \mathrm{cc}$. lower.

It was mentioned above that a rise of $1 \mathrm{~cm}$. water in venous pressure (above $17 \mathrm{~cm}$. water) increased the average filtration rate by $.0023 \mathrm{cc}$. per minute per $100 \mathrm{cc}$. When the change in filtration rate in the standing position is divided by the change in colloid osmotic pressure it is found that a rise of $1 \mathrm{~cm}$. water in colloid osmotic pressure is accompanied by a decrease in filtration rate of .0027 to $.0045 \mathrm{cc}$. per minute per $100 \mathrm{cc}$.

The colloid osmotic pressure of the blood was also increased in the recumbent subject by venous congestion of the legs. Two large pneumatic cuffs were placed around the thighs and inflated to a pressure of 
$65 \mathrm{~cm}$. water for a period of 2 to 3 hours. Filtration rates were determined at intervals while the blood was being concentrated and compared with repeated colloid osmotic pressure determinations. There was always a diminution in the rate of filtration as the colloid osmotic pressure of the blood increased. The change in filtration per unit change in colloid osmotic pressure was in one instance below .0023 , but in all other instances above, agreeing with the standing experiments. The total change in colloid osmotic pressure was less and the results were therefore much less uniform than those obtained during standing.

\section{DISCUSSION}

It was realized throughout these studies that a method which required as much modification of circulation as the one described above must be controlled carefully to avoid improper conclusions based on artefacts. It has already been shown in connection with Fig. 3 and Table 1 that within the limits of these experiments variations in the amount of blood contained in the vessels prior to the determination did not introduce significant errors into the final readings of reduced arm volume. Two other possible sources of error remain to be considered: first, the possible filtration produced by the reactive hyperemia which followed each determination of reduced arm volume, and second, the possible squeezing out of tissue fluid by the external pressure applied to the arm.

The reactive hyperemia which followed each 4 to 6 minute period of occlusion elevated venous pressure in the hand (Protocol 1) only during the first 1 to 2 minutes of the recovery period. This venous pressure, always less than $27 \mathrm{~cm}$. water, was not sufficient to modify the arm volume permanently as shown by the constancy of the readings during the control period which preceded each experiment. The small amount of fluid filtered during the minute or two when venous pressure was thus elevated could easily be reabsorbed in the period when venous pressure was again below $15 \mathrm{~cm}$. water.

It was also possible to show that the application of $55 \mathrm{~cm}$. water pressure to the skin did not express a significant volume of fluid from the segment of arm within the plethysmograph. The lymphatic vessels were doubtless emptied in the same way as the blood vessels, and it is very unlikely that tissue fluid could be expressed by $55 \mathrm{~cm}$. water pressure into lymph or blood capillaries collapsed by the same pressure. The direct movement of fluid through the tissue spaces out of the arm segment was prevented by the small external bags above and below the plethysmograph which were also inflated to $55 \mathrm{~cm}$. water pressure. Moreover, if fluid had been mechanically expressed during the periods when external pressure was applied it would be expected that when reduced arm volumes were determined more frequently the removal of fluid should be hastened. This was tested several times and, as shown 
to the right in Fig. 7, the rate of removal was not appreciably raised in the period when volume determinations were made twice as frequently.

The purpose of the experiments was to study certain factors in fluid balance between blood and tissue spaces under physiological conditions, and for that reason low venous pressures and the smallest possible amounts of fluid were dealt with. Filtration was observed with degrees of venous congestion which must exist normally when the arm hangs relaxed at the side of the body. The total amounts of fluid accumulating in the tissues were never more than $1 / 4$ the amount required to produce a pitting edema. The term "edema fluid" has not been used, since the word edema ordinarily refers to pathological accumulations of fluid, which are large enough to distend the tissues visibly, or at least large enough to pit on pressure.

The results demonstrate that fluid accumulates in the tissue spaces when average venous pressure is above $17 \mathrm{~cm}$. water. This indicates the existence of a small but definite margin of safety through which venous pressure may be increased without gross disturbance of fluid balance. A similar margin of safety has been observed in certain clinical conditions which are accompanied by a reduction of the colloid osmotic pressure of the blood below its normal value of about $36 \mathrm{~cm}$. water. Iversen and Nakazawa (1927) state that edema appeared in ambulant patients when the colloid osmotic pressure was reduced to between 24 and $27 \mathrm{~cm}$. water, while Mayrs (1926) observed that after recovery from nephritis edema disappeared when the colloid osmotic pressure rose to between 20 and 23 $\mathrm{cm}$. water. In a case of inanition edema Landis and Leopold (1930) found that the edema disappeared when the colloid osmotic pressure was elevated to $24 \mathrm{~cm}$. water by blood transfusion. Thus the colloid osmotic pressure of the blood must be reduced by from 9 to $16 \mathrm{~cm}$. water before edema appears, while venous pressure must be elevated to between 15 and $20 \mathrm{~cm}$. water before fluid begins to accumulate in the tissue spaces. As might be expected the agreement is better in the comparison with recumbent patients (Mayrs, 1926; Landis and Leopold, 1930) than with ambulant patients (Iversen and Nakazawa, 1927).

This margin of safety is much less than that found by Mende (1919) in certain experiments involving venous congestion. The venous pressures which he found to be associated with the first measurable filtration must have been too high since change in limb volume was estimated by measuring the circumference of the limb, a method which is totally inadequate for the detection of small accumulations of fluid. In addition the congestion was produced by a narrow pneumatic cuff so that true venous pressure must have been significantly less than the pressure in the cuff itself.

The relationship between the gradient of capillary pressure and the colloid osmotic pressure of the blood offers an explanation of this margin 
of safety. According to direct measurements in human skin (Landis, 1930) average capillary pressure in the arteriolar loop is $43 \mathrm{~cm}$. water and in the venous loop, $16 \mathrm{~cm}$. water. The normal colloid osmotic pressure of the blood is about 35 to $36 \mathrm{~cm}$. water. Thus blood pressure in the arteriolar end of the capillary system is only 7 to $8 \mathrm{~cm}$. water higher than the colloid osmotic pressure of the blood, while capillary pressure in the venous end of the capillary system is from 19 to $20 \mathrm{~cm}$. lower than colloid osmotic pressure, the difference becoming still greater in the subpapillary venous plexus, or in the first venous network. Even if the filtering and absorbing surfaces were exactly equal in area, the balance would favor absorption, as long as the capillary wall was almost or completely impermeable to protein. It is practically certain also in the case of skin, and quite likely in the case of muscle, that the absorbing surface is greater in extent than the filtering surface. This would probably provide a slight margin of safety even if the capillary wall in mammals were normally permeable to protein to the extent claimed by Harrop and Waterfield (1930) and by Drinker and Field (1931).

To produce a preponderance of filtration it would be necessary to raise venous pressure until the average difference between capillary pressure and colloid osmotic pressure in the absorbing area. was slightly less than the average difference between these two pressures in the filtering area. With the figures given above this should occur at slightly over 25 cm. water pressure. Actually, tissue fluid might be expected to accumulate at a slightly lower pressure since venous congestion must also raise the pressure in the arteriolar end of the capillary network to a slight extent.

The effectiveness of 20 and $30 \mathrm{~cm}$. water pressure in preventing the removal of fluid from the tissues, when the total accumulation was less than $.6 \mathrm{cc}$. per $100 \mathrm{cc}$. of arm, makes it likely that with such small accumulations the fluid is removed chiefly by true absorption. This must depend primarily upon the slight excess of colloid osmotic pressure over average capillary pressure, when the capillary area is considered as a whole. It is possible to compute the average pressure through the whole capillary area from this rate of absorption. A difference of $1 \mathrm{~cm}$. water in venous pressure changed the filtration rate by $.0023 \mathrm{cc}$. per minute per 100 cc. (Fig. 6). Normal absorption (Table 2) occurred at the rate of.026 cc. per minute per $100 \mathrm{cc}$. Average pressure through the whole capillary network and the subpapillary venous plexus must therefore have been $11 \mathrm{~cm}$. water lower than average colloid osmotic pressure. With a colloid osmotic pressure of 35 to $36 \mathrm{~cm}$. water, average capillary pressure must have been about 24 to $25 \mathrm{~cm}$. water. This agrees with the direct measurements (Landis, 1930), in which average pressure in the arteriolar loop was $43 \mathrm{~cm}$. water, and in the venous loop $16 \mathrm{~cm}$. water. A difference of $1 \mathrm{~cm}$. water in colloid osmotic pressure produced an average change in filtration 
rate of $.0036 \mathrm{cc}$. per minute per $100 \mathrm{cc}$., and this figure, used in a similar calculation, indicates that capillary pressure was between 28 and $29 \mathrm{~cm}$. water.

When more than $.6 \mathrm{cc}$. of fluid per $100 \mathrm{cc}$. had been filtered, venous congestions of 15,20 and at times even of $30 \mathrm{~cm}$. water pressure failed to cause an increase in the volume of tissue fluid. With a venous pressure of $15 \mathrm{~cm}$. water tissue fluid was removed at the usual rate, and even 20 $\mathrm{cm}$. water pressure diminished the rate of removal very slightly. This in itself indicates that some other factor was favoring the removal of fluid and hindering a further increase in the volume of tissue fluid. This can be shown also by a calculation similar to that given in the preceding paragraph. In Table 2 it is shown that with a venous pressure of $15 \mathrm{~cm}$. water the fluid was removed at the average rate of $.055 \mathrm{cc}$. per minute per $100 \mathrm{cc}$. If this were done by absorption alone it would require an average capillary pressure between 11 and $12 \mathrm{~cm}$. water. Venous pressure, however, was $15 \mathrm{~cm}$. water and since capillary pressure cannot be less than this, it is obvious that another factor must be involved in the removal of these larger volumes of fluid. Similar calculations applied to the movement of fluid during congestion at 20 and $30 \mathrm{~cm}$. lead to the same conclusion.

Two factors that may be concerned with the more rapid removal of the larger collections of fluid are tissue turgor and lymphatic drainage. It is unlikely that tissue turgor plays an important part because it would require tissue pressures of as much as $15 \mathrm{~cm}$. water to modify the rate of fluid removal to the extent shown in Table 2. It is more likely, when larger amounts of fluid have collected in the tissue spaces, that fluid passes into the lymphatic vessels at a rate which can exceed the rates of filtration produced by venous pressures of 15,20 , or $30 \mathrm{~cm}$. of water.

The rate at which edema forms when the veins of the leg are congested has been studied by Drury and Jones (1927). They used an ordinary plethysmograph but by prolonging the periods of observation to $30 \mathrm{~min}$ utes, and by using relatively high grades of venous congestion ( 40 to 80 $\mathrm{mm} . \mathrm{Hg}$ ), they apparently avoided the irregularities resulting from spontaneous vasomotor variations. They showed that when temperature was increased $10^{\circ} \mathrm{C}$. the rates of filtration became conspicuously higher. Comparison can be made therefore only with the filtration rates they observed at the temperature of $26^{\circ} \mathrm{C}$. The filtration rates observed in the leg at high venous pressures were very much less than those observed in the arm at lower venous pressures. This must be related to the greater proportion of bone in the leg and particularly in the foot, which would reduce the rate of filtration per $100 \mathrm{cc}$. of tissue. Only three congestion pressures were used by Drury and Jones, but the corresponding filtration rates fell on a straight line, in agreement with the findings in the arm. Moreover, from the slope of this line, it may be concluded that at $26^{\circ} \mathrm{C}$. 
a venous pressure somewhat less than $20 \mathrm{~cm}$. of water would be sufficient to produce the accumulation of fluid in the tissue spaces of the leg.

The change in filtration rate accompanying a change of $1 \mathrm{~cm}$. water in venous pressure was $.0023 \mathrm{cc}$. per minute per $100 \mathrm{cc}$. The change in filtration rate accompanying the same unit change in the colloid osmotic pressure of the blood was .0027 to $.0045 \mathrm{cc}$. per minute per $100 \mathrm{cc}$. The filtration differences are of the same order of magnitude but nevertheless a rise of $1 \mathrm{~cm}$. in colloid osmotic pressure was accompanied uniformly by a greater change in filtration than was the case with a corresponding change in venous pressure. All other factors remaining constant it would be expected theoretically that the effect of unit change in these two forces would be identical. It is probable, however, that extraneous factors have made the first figure lower, and the second figure higher, than the correct value.

When venous pressure is raised by $1 \mathrm{~cm}$. water, it does not follow that general capillary pressure throughout the entire network is also raised by the same amount, because of the gradient of pressure fall in the capillary network. As blood flow is diminished by the higher grades of congestion the pressure gradient in the capillary network would be reduced and the blood in the filtering area would be renewed at a slower rate. Both of these changes would tend to diminish the slope of the straight line in Fig. 6. This is compatible even with a straight line relationship between venous pressure and filtration rate since the correspondence between venous and capillary pressures must depend upon the grade of venous congestion. The real change in filtration rate which accompanies a change of $1 \mathrm{~cm}$. water in capillary pressure is therefore probably slightly greater than $.0023 \mathrm{cc}$. per minute per $100 \mathrm{cc}$.

It is certain that standing modifies the mechanics of circulation and that the vascular system responds with varying efficiency to changes in posture (Turner, Newton and Haynes, 1930). In the standing position the volume of blood available for general circulation must be reduced not only by the blood distending the abdominal and leg veins, but also by the fluid which filters into the leg tissues. After prolonged periods in the standing position the diminution of circulating blood volume may produce dizziness or actual fainting. In one subject (A. T.) it was necessary to diminish the dizziness by slow movements of the legs during the latter part of the standing periods. This dizziness or fainting indicates that blood flow in the more elevated portions of the body must be reduced by the stagnation of blood in the more dependent parts. A diminution of blood flow through the arm would tend to flatten the gradient of capillary pressure in those portions of the network where it exceeded the congestion pressure. Moreover, less fluid would be filtered at a given venous pressure because the blood in the arm would be renewed at a slower rate. Both changes would tend to diminish the filtration of fluid. Since stand- 
ing produced not only an increase in colloid osmotic pressure, but also circulatory changes of the nature described, the change in filtration rate was probably greater than that produced by colloid osmotic pressure changes alone. An attempt to dissociate the change in filtration due to the vascular factor from that due to change in colloid osmotic pressure was unsuccessful since in the normal subject an increase in blood colloid osmotic pressure could be obtained only by methods which also diminished the volume of the circulating blood.

It seems probable that a rise of $1 \mathrm{~cm}$. in colloid osmotic pressure is accompanied by a diminution of filtration rate which is something less than .0027 to $.0045 \mathrm{cc}$. per minute per $100 \mathrm{cc}$., while a rise of $1 \mathrm{~cm}$. in capillary pressure is accompanied by an increase of filtration rate which is something more than $.0023 \mathrm{cc}$. per minute per $100 \mathrm{cc}$. The true change in filtration rate produced by these two forces should be numerically identical, and probably lies somewhere between the two figures observed. The experiments present no evidence which is incompatible with the application of the Starling conception of fluid balance to man.

The above calculations could be made only with the basic assumption that the normal capillary wall is at most very slightly permeable to protein, so that the effective colloid osmotic pressure is practically equivalent to the total colloid osmotic pressure of the blood. But if tissue fluid and lymph are wholly identical as claimed by Drinker and Field (1931) the outer surface of the capillary wall must be bathed in a fluid containing between 2 and 3 per cent of protein.

It is difficult to associate the margin of safety observed in the studies described above with the very low effective colloid osmotic pressure that must result from the presence of an extravascular fluid containing from $1 / 3$ to $1 / 2$ as much protein as blood. In addition, if the fluid, as filtered through the capillary wall, had contained from 2 to 3 per cent protein, the absorption of the smaller accumulations of tissue fluid (Fig. 7) should have been stopped by this protein and arm volume should not have returned to normal. It would be expected, too, that with such a reduction in effective colloid osmotic pressure, the change in filtration rate per unit change of total colloid osmotic pressure should have been less than the change in filtration rate with unit change of venous pressure, whereas actually the reverse was found.

A possible mechanism of lymph formation suggested by Drinker and Field $(1931$, p. 36$)$ is that ". . . the filtrate from the blood capillaries to the tissue spaces contains water, salts and sugar in the concentrations of the blood, together with serum globulin, serum albumin and fibrinogen in low concentration, lower probably than that of tissue fluid or lymph; that water and salts are reabsorbed by the blood vessels and the protein enters the lymphatics together with water and salts in the concentration existing in the tissue fluid at the moment of lymphatic entrance." 
According to this view, however, tissue fluid must vary from a filtrate with low protein content, immediately about the filtering capillary area, to a concentrated fluid containing more protein, near the absorbing areas and adjacent to the lymphatics. Lymph, being composed of the latter type of tissue fluid, must usually have a higher protein concentration than the average tissue fluid bathing the outside of the capillary wall. Analyses of lymph cannot, in general, provide definite information concerning the average protein content of the tissue fluid surrounding the capillary wall. The protein in lymph must vary widely, depending, among other things, on the rate of filtration and the relative amount of absorption. The slower the filtration and the more complete the reabsorption, the more will the composition of lymph differ from that of the capillary filtrate, and from that of average tissue fluid. The more rapid the filtration and the less complete the reabsorption, the more nearly will both average tissue fluid and lymph resemble the fluid filtered through the capillary wall.

In certain mechanical filtration edemas the extravascular fluid has been found to contain very low concentrations of protein, even considerably below 0.1 per cent (Beckmann, 1921; Achard, 1930; Landis and Leopold, 1930). In edema of this type the pressure conditions favor filtration and probably diminish absorption considerably. The composition of the tissue fluid must therefore resemble that of the capillary filtrate quite closely.

From the data available at present, it seems most likely that the normal capillary wall is not absolutely impermeable to protein, and that an exceedingly slight leakage of protein occurs rather generally. The concentration of protein in the capillary filtrate can certainly be less than 0.1 per cent, and the relatively high protein content of lymph is probably due to reabsorption of water and salts from the original capillary filtrate. The changes in filtration rate produced by changes in venous pressure and in the colloid osmotic pressure of the blood are in accord with this view.

\section{SUMMARY}

The movement of fluid through the human capillary wall was studied by means of a pressure plethysmograph, which collapsed the blood vessels and thus permitted the accurate determination of small changes in tissue volume. It was shown that within certain limits the determinations of volume change were not significantly influenced by hyperemia or by previous engorgement of the veins.

Fluid accumulated in the tissue spaces when venous pressure was greater than 15 or $20 \mathrm{~cm}$. water. Above an average venous pressure of $17 \mathrm{~cm}$. water the rate of filtration was directly proportional to the increase in venous pressure. A unit rise in venous pressure $(1 \mathrm{~cm}$. water) increased the filtration rate by $.0023 \mathrm{cc}$. per minute per $100 \mathrm{cc}$. of arm. 
The rate at which fluid was removed from the tissue spaces depended on the size of the accumulation of fluid, being distinctly more rapid with large amounts. When less than $.6 \mathrm{cc}$. of fluid per $100 \mathrm{cc}$. of arm was present, the removal of fluid was retarded by elevating venous pressure to 15 or $20 \mathrm{~cm}$. water, which was taken to indicate that small amounts of fluid were removed chiefly by true absorption. When more than $.6 \mathrm{cc}$. of fluid per $100 \mathrm{cc}$. of arm was present the fluid was removed in spite of slight grades of venous congestion. In this connection the relative importance of tissue turgor and lymphatic drainage is briefly considered.

When the colloid osmotic pressure of the blood was elevated by standing, the rate of filtration produced by a given venous pressure was uniformly lower. A unit rise in colloid osmotic pressure $(1 \mathrm{~cm}$. water) was accompanied by a fall in filtration rate varying between .0027 and .0045 cc. per minute per $100 \mathrm{cc}$. of arm.

The observations are discussed with reference to capillary pressure and fluid balance in man.

\section{BIBLIOGRAPHY}

1. Achard, Ch., The Oedema of Bright's Disease. Kegan Paul, London, 1930.

2. Beckmann, K., Deut. Arch. f. klin. Med., 1921, cxxxv, 39. Untersuchungen über den Eiweissgehalt und intermediären Zucker-, Wasser-, Harnsäure-, und Kochsalzwechsel bei verschiedenen Ödemformen.

3. Carrier, E. B., and Rehberg, P. B., Skandinav. Arch. f. Physiol., 1923, xliv, 20. Capillary and Venous Pressure in Man.

4. Drinker, C. K., and Field, M. E., Am. J. Physiol., 1931, xcvii, 32. The Protein Content of Mammalian Lymph and the Relation of Lymph to Tissue Fluid.

5. Drury, A. N., and Jones, N. W., Heart, 1927, xiv, 55. Observations upon the Rate at Which Oedema Forms When the Veins of the Human Limb Are Congested.

6. Govaerts, P., Bull. Acad. roy. de méd. de Belgique, 1924, iv, 161. Recherches cliniques sur le rôle de la pression osmotique des protéines du sang dans la pathogénie des oedèmes et de l'hypertension artérielle.

7. Hagedorn, H. C., Rasmussen, P., and Rehberg, P. B., cited by Krogh, 1922 , p. 265.

8. Harrop, G. A., Jr., and Waterfield, R. L., Proc. Physiol. Soc., J. Physiol., 1930, lxx, xxxii. The Effect of Posture on the Composition and Volume of the Blood and on its Selective Diffusion into the Lymph Spaces.

9. Iversen, P., and Nakazawa, F., Biochem. Ztschr., 1927, cxci, 307. Über die Biochemie des Filtrationsödems.

10. Krogh, A., The Anatomy and Physiology of the Capillaries. Yale University Press, New Haven, 1922.

11. Krogh, A., The Anatomy and Physiology of the Capillaries, revised edition. Yale University Press, New Haven, 1929.

12. Krogh, A., and Nakazawa, F., Biochem. Ztschr., 1927, clxxxviii, 241. Beiträge zur Messung des kolloid-osmotischen Druckes in biologischen Flüssigkeiten.

13. Krogh, A., Turner, A., and Landis, E. M., J. Clin. Invest., 1932 (in press). A Celluloid Capsule for Measuring Venous Pressures. 
14. Landis, E. M., Am. J. Physiol., 1926, lxxv, 548. The Capillary Pressure in Frog Mesentery as Determined by Micro-Injection Methods.

15. Landis, E. M., Am. J. Physiol., 1930, xciii, 353. The Capillary Blood Pressure in Mammalian Mesentery as Determined by the MicroInjection Method.

16. Landis, E. M., Heart, 1930, xv, 209. Micro-Injection Studies of Capillary Blood Pressure in Human Skin.

17. Landis, E. M., and Leopold, S. S., J. Am. Med. Assoc., 1930, xciv, 1378. Inanition Edema Associated with Tuberculous Enteritis.

18. Leiter, L., Proc. Soc. Exp. Biol. and Med., 1928, xxvi, 173. Experimental Edema.

19. Lewis, T., and Grant, R., Heart, 1925, xii, 73. Observations upon Reactive Hyperemia in Man.

20. Mayrs, E. B., Quart. J. Med., 1926, xix, 273. The Functional Pathology of Nephritis.

21. Mende, D., Deutsches Ztschr. f. Chir., 1919, cl, 379. Über Hyperämie und Ödem bei der Hemmung der Rückflusses des venösen Blutes durch die Staubinde.

22. Ni, T., and Rehberg, P. B., J. Physiol., 1931, lxxi, 331. On the Influence of Posture on Kidney Function.

23. Rowe, A. H., J. Lab. and Clin. Med., 1916, i, 485. The Effect of Venous Stasis on the Proteins of Human Blood Serum.

24. Schade, H., and Claussen, F., Ztschr. f. klin. Med., 1924, c, 363 . Der onkotische Druck des Blutplasmas und die Entstehung der renal bedingten Ödeme.

25. Thompson, W. O., Thompson, P. K., and Dailey, M. E., J. Clin. Invest., 1927-8, v, 573. The Effect of Posture upon the Composition and Volume of the Blood in Man.

26. Turner, A. H., Newton, M. I., and Haynes, F. W., Am. J. Physiol., 1930, xciv, 507. The Circulatory Reaction to Gravity in Healthy Young Women. 